\title{
Educação Inclusiva para Pessoas com Deficiência: Protagonismo Docente e combate ao Preconceito
}

\author{
Inclusive Education for People With \\ Disabilities: Teacher's Protagonism and combat \\ Prejudice
}

\author{
Educación Inclusiva para Personas con \\ Discapacidades: Enseñar el Protagonismo y \\ combatir el Prejuicio
}

\author{
Gabriela Natacha Bechara* \\ Horácio Wanderlei Rodrigues ** \\ Marcelo Vitor Silva Rizzo ${ }^{* * *}$
}

1 Introdução. 2 Educação inclusiva no Direito brasileiro. 3 Educação inclusiva: uma necessidade. 4 Educação inclusiva e combate ao preconceito. 5 Papel docente. 6 Considerações finais. Referências.

Doutora e Mestre em Direito pela UFSC. Professora do Curso de Graduação em Direito do UNIVEM. Professora Permanente e Coordenadora Adjunta do PPGD/UNIVEM. Coordenadora do NAPEx/UNIVEM. Marília, SP, BR. E-mail: <gbechara@gmail.com>. https://orcid.org/0000-00019694-1275

** Doutor e Mestre em Direito pela UFSC. Estágios de Pós-Doutorado em Filosofia/UNISINOS e em Educação/UfRGS. Professor Permanente e Coordenador do PPGD/UNIVEM e Professor Convidado do PPGD/UNICURITIBA. Professor Titular (aposentado) do DIR/UFSC. Membro do Instituto Iberomericano de Derecho Procesal. Sócio-fundador do CONPEDI e da ABEDi. Bolsista de Produtividade em Pesquisa do CNPq. Marília, SP, BR. E-mail: 〈horaciowr@gmail.com>. http://orcid.org/0000-0003-2887-5733

*** Mestrando em Teoria do Direito e do Estado no Centro Universitário Eurípides de Marília (UNIVEM). Bacharel em Direito pelo UNIVEM. Membro do Grupo de Pesquisa DiFuSo. Marília, SP, BR. E-mail: <mavsrizzo@gmail.com>. https://orcid.org/0000-0002-4579-9106 


\title{
RESUMO
}

Objetivos: $\mathrm{O}$ presente trabalho tem por objetivos demonstrar que a educação inclusiva é um instrumento de combate ao preconceito, bem como observar o papel central exercido pelo professor nesse processo. A pesquisa buscou compreender o que é educação inclusiva, como nela está inserida a educação das pessoas com deficiência e a legislação vigente. Este estudo ficou restrito à educação inclusiva das pessoas com deficiência - a inclusão, em sentido amplo, seria de qualquer minoria que é excluída ou segregada e exigiria um trabalho de mais fôlego.

Metodologia: A pesquisa foi documental e bibliográfica, de caráter qualitativo, com natureza exploratória, e trabalhou com raciocínio dedutivo. A questão que buscou ser respondida é se a educação inclusiva das pessoas com deficiência é uma forma de combate ao preconceito na sociedade e qual seria o papel do professor nesse processo.

Resultado: Conclui-se que a educação inclusiva das pessoas com deficiência é uma forma de combate ao preconceito no Brasil, pois torna cotidiana a convivência entre os alunos, com ou sem deficiência, estreitando laços e relações, e que o professor é o principal, mas não o único ator e fator de aplicação da educação inclusiva.

Contribuições: A pesquisa demonstrou que o tema explorado é de grande relevância social e acadêmica - delicado e alvo de muita discussão na sociedade. Com relação ao papel do professor, a pesquisa destaca que seu papel é determinante no sucesso da educação inclusiva, sendo necessário, entretanto, que possua adequada formação pedagógica.

Palavras-chave: Educação inclusiva. Pessoas com deficiência. Preconceito. Formação pedagógica. Professor.

\begin{abstract}
Objectives: The present work aims to demonstrate that inclusive education is an instrument to combat prejudice, as well as the central role played by the teacher in this process. The research sought to understand what inclusive education is, how it is inserted in the education of people with disabilities and the current legislation. The research was restricted to the inclusive education of people with disabilities - inclusion, in a broad sense, would be of any minority that is excluded or segregated and would require a more vigorous work.
\end{abstract}

Methodology: The research was documental and bibliographic, of qualitative character, with exploratory nature, working with deductive reasoning. The question that sought to be answered is whether the inclusive education of people with disabilities is a way of fighting prejudice in society and what would be the role of the teacher in this process. 
Result: It is concluded that the inclusive education of people with disabilities is a way of fighting prejudice in Brazil, as it makes students, with or without disabilities, to socialize every day, strengthening ties and relationships. And that the teacher is the main, but not the only actor and factor in the application of inclusive education.

Contributions: Research has shown that a topic is of great social and academic relevance - delicate and subject to much discussion in society. Regarding the role of the teacher, the research highlights that his role is decisive in the success of inclusive education, being necessary, however, that he has adequate pedagogical training.

Keywords: Inclusive education. People with Disabilities. Prejudice. Pedagogical formation. Teacher.

\section{RESUMEN}

Objetivos: El presente trabajo tiene como objetivo demostrar que la educación inclusiva es un instrumento para combatir los prejuicios, así como el papel central que desempeña el profesor en este proceso. La investigación buscó comprender qué es la educación inclusiva, cómo se inserta en la educación de las personas con discapacidad y la legislación actual. La investigación se limitó a la educación inclusiva de las personas con discapacidad: la inclusión, en un sentido amplio, sería de cualquier minoría que esté excluida o segregada y requeriría un trabajo más vigoroso.

Metodología: La investigación fue documental y bibliográfica, de carácter cualitativo, con carácter exploratorio, trabajando con razonamiento deductivo. La pregunta que buscaba respuesta es si la educación inclusiva de las personas con discapacidad es una forma de combatir los prejuicios en la sociedad y cuál sería el papel del maestro en este proceso.

Resultado: Se concluye que la educación inclusiva de las personas con discapacidad es una forma de combatir los prejuicios en Brasil, ya que hace que la vida cotidiana entre los estudiantes, con o sin discapacidad, fortalezca los lazos y las relaciones. Y que el maestro es el principal, pero no el único actor y factor en la aplicación de la educación inclusiva.

Contribuciones: La investigación ha demostrado que el tema es de gran relevancia social y académica, delicado y sujeto a mucha discusión en la sociedad. Con respecto al papel del maestro, la investigación destaca que su papel es decisivo en el éxito de la educación inclusiva, siendo necesario, sin embargo, que tenga una formación pedagógica adecuada.

Palabras clave: Educación inclusiva. Personas con deficiencia. Prejuicio. Entrenamiento pedagógico. Profesor. 


\section{INTRODUÇÃO}

De acordo com o Censo Demográfico, realizado em 2010, 24\% da população brasileira, ou seja, quase 46 milhões de pessoas, afirmam possuir algum grau de dificuldade ao enxergar, ouvir, caminhar ou subir degraus, bem como possuir deficiência mental/intelectual (IBGE, 2010).

Por conseguinte, parece que expressiva parcela da população brasileira possui algum tipo de deficiência que permeia seu cotidiano, muitas vezes, perpassado por vulnerabilidades e preconceitos em suas mais variadas formas. Essa massa populacional está inserida em um contexto de uma sociedade despreparada para lidar com essa diversidade.

Nesse sentido, a educação de pessoas com deficiência revela-se ainda como um grande desafio no Brasil, apesar dos dispositivos legais que tratam dessa matéria. Assim, considerando-se a problemática e a importância da educação das pessoas com deficiência, apresenta-se como necessário entender como tem sido aplicada a educação inclusiva no país.

A pesquisa que deu origem a este artigo teve como objeto investigar acerca da educação inclusiva. A questão que buscou ser respondida é se a educação inclusiva das pessoas com deficiência é uma forma de combate ao preconceito na sociedade e qual seria o papel do professor nesse processo.

A hipótese trabalhada é afirmativa, pois considera-se que a educação inclusiva traz benefícios para a sociedade e combate o preconceito ao estreitar os laços existentes nas relações humanas entre os diferentes sujeitos, que aprendem, por meio da educação inclusiva, a respeitar e a conviver com a diferença do outro.

Com relação ao papel do professor, considerado um dos principais atores da educação, entende-se que sua atuação nesse processo é determinante no sucesso da educação inclusiva, desde que possua uma adequada preparação pedagógica na educação inclusiva.

Este estudo tem relevância, tanto social quanto jurídica, por existirem inúmeras pessoas com deficiência que sofrem segregação diária, mesmo havendo previsão constitucional para sua proteção.

Para a realização da pesquisa, foi utilizada análise documental e pesquisa bibliográfica, além disso, trabalhou-se com o raciocínio dedutivo. Essa análise foi configurada, ainda, como uma pesquisa qualitativa, levando em consideração que não houve levantamento e análise de dados. 


\section{EDUCAÇÃO INCLUSIVA NO DIREITO BRASILEIRO}

No Brasil, a Constituição Federal, assim como também a legislação infraconstitucional, preveem a educação inclusiva e, em especial, a educação especial para pessoas com deficiência - foco deste artigo.

Especificamente no que tange à educação, a Carta Constitucional, em seu Capítulo III - que dispõe sobre a ordem social - trata do tema entre os artigos 205 a 214. Considerando o escopo deste trabalho, merece destaque, entre os citados, o seguinte dispositivo:

Art. 205. A educação, direito de todos e dever do Estado e da família, será promovida e incentivada com a colaboração da sociedade, visando ao pleno desenvolvimento da pessoa, seu preparo para o exercício da cidadania e sua qualificação para o trabalho (BRASIL, 1988, online).

O supramencionado dispositivo enfatiza que a educação é, de um lado, direito de todos, e, de outro, que o dever de seu oferecimento é compartilhado, cabendo ao Estado e à família, com a colaboração da sociedade, ou seja, não se trata de um dever pertencente exclusivamente ao Estado.

Entende-se, também, que a Constituição atribui ao Estado a responsabilidade de manter sistemas de ensino nos quais todo ser humano, enquanto estudante, possa desenvolver-se plenamente, preparando-se para o exercício da cidadania e para o futuro enquanto profissional.

Já o artigo 206 elenca entre os princípios norteadores do processo educacional a "igualdade de condições para o acesso e permanência na escola" (inciso I) e a "garantia de padrão de qualidade" (inciso VII) (BRASIL, 1988, online).

Fazendo menção explícita às pessoas com deficiência, a Carta Magna também prevê que:

Art. 208. O dever do Estado com a educação será efetivado mediante a garantia de:

[...]

III - atendimento educacional especializado aos portadores de deficiência, preferencialmente na rede regular de ensino;

$[\ldots]$

$\mathrm{V}$ - acesso aos níveis mais elevados do ensino, da pesquisa e da criação artística, segundo a capacidade de cada um; (BRASIL, 1988, online, grifo nosso).

O artigo 208 delimita como o Estado efetiva seu dever com a educação. Concernente à educação inclusiva, tem-se que, em sua atuação para garantir a educação, o Estado deve dispensar atendimento especializado às pessoas com deficiência, 
assegurando acesso ao nível educacional segundo a capacidade de cada indivíduo (incisos III e V do artigo 208, respectivamente).

Com relação à expressão "portadores de deficiência”, utilizada na redação do inciso III do artigo 208 da Constituição, parece oportuno mencionar que sua utilização respeitava o entendimento vigente na época, contudo hoje não se revela mais como adequada. Essa referência se faz necessária em virtude do tempo e das modificações ocorridas desde então, uma vez que a expressão foi abandonada, pois reforçaria a ideia de exclusão dessa parcela da população. Isso porque o uso da palavra "portador" remeteria à ideia de que a pessoa pode desfazer-se de sua condição ou de que esta é temporária, ainda que normalmente permanente. De tal sorte, a expressão foi substituída por "pessoa com deficiência", tida como mais adequada, pois ressalta a pessoa, e não sua deficiência, considerando-a independentemente de suas condições físicas, intelectuais e sensoriais. ${ }^{1}$

Por fim, com relação ao texto constitucional, em um escopo mais abrangente e principiológico de suas diretrizes, a Carta Magna brasileira estabelece ambiciosos fundamentos e objetivos, entre eles o fundamento da dignidade da pessoa humana (artigo 1\%) e o objetivo fundamental de "construir uma sociedade livre, justa e solidária" (artigo 3º inciso I) (BRASIL, 1988, online), que podem ser invocados quando se pensa em educação inclusiva.

Feitas essas considerações com relação ao previsto constitucionalmente, cabe destaque o fato de que o Brasil é signatário da Declaração de Salamanca², realizada no ano de 1994, responsável pela definição de grande parte do roteiro de inclusão educacional contemporânea.

Positivando seus entendimentos quanto aos direitos das pessoas com deficiência, seus delegatários acreditam e proclamam que:

- toda criança tem direito fundamental à educação, e deve ser dada a oportunidade de atingir e manter o nível adequado de aprendizagem;

- toda criança possui características, interesses, habilidades e necessidades de aprendizagem que são únicas;

- sistemas educacionais deveriam ser designados e programas educacionais deveriam ser implementados no sentido de se levar em conta a vasta diversidade de tais características e necessidades;

1 O mesmo entendimento pode ser aplicado a outros termos, como "portador de necessidades especiais" e "pessoa portadora de deficiência".

2 Realizada entre 7 e 10 de junho de 1994, na cidade espanhola de Salamanca, a Conferência Mundial sobre Necessidades Educacionais Especiais resultou em um documento intitulado de Declaração de Salamanca, que reduz a termo Princípios, Políticas e Práticas na Área das Necessidades Educativas Especiais, reconhecendo a necessidade e a urgência de providenciar educação para as crianças, os jovens e os adultos com necessidades educacionais especiais dentro do sistema regular de ensino. 
- aqueles com necessidades educacionais especiais devem ter acesso à escola regular, que deveria acomodá-los dentro de uma Pedagogia centrada na criança, capaz de satisfazer a tais necessidades;

- escolas regulares que possuam tal orientação inclusiva constituem os meios mais eficazes de combater atitudes discriminatórias criando-se comunidades acolhedoras, construindo uma sociedade inclusiva e alcançando educação para todos; além disso, tais escolas proveem uma educação efetiva à maioria das crianças e aprimoram a eficiência e, em última instância, o custo da eficácia de todo o sistema educacional (UNESCO,1994, p. 8-9, grifo nosso).

Por sua vez, já na seara da legislação infraconstitucional, merece destaque a Lei n. ${ }^{\circ}$ 13.005/2004 (BRASIL, 2014), que trata do Plano Nacional da Educação - PNE e dá outras providências. Essa lei estabelece algumas importantes diretrizes para a educação no Brasil, entre elas a universalização do atendimento escolar, a superação das desigualdades educacionais, com ênfase na promoção da cidadania e na erradicação de todas as formas de discriminação, e a promoção dos princípios do respeito aos direitos humanos, à diversidade e à sustentabilidade socioambiental.

No tocante às pessoas com deficiência, o PNE estabelece a Meta 4, enfatizando o direito à Educação Básica e ao atendimento educacional especializado de forma inclusiva:

Meta 4: universalizar, para a população de 4 (quatro) a 17 (dezessete) anos com deficiência, transtornos globais do desenvolvimento e altas habilidades ou superdotação, o acesso à educação básica e ao atendimento educacional especializado, preferencialmente na rede regular de ensino, com a garantia de sistema educacional inclusivo, de salas de recursos multifuncionais, classes, escolas ou serviços especializados, públicos ou conveniados (BRASIL, 2014, online).

Ainda em sede infraconstitucional, encontra-se a Lei n. ${ }^{\circ}$ 13.146/2015, que institui a Lei Brasileira de Inclusão da Pessoa com Deficiência - LBPD, ou, ainda, o Estatuto da Pessoa com Deficiência. Essa Lei, logo em seu artigo 1\%, declara ser "[...] destinada a assegurar e a promover, em condições de igualdade, o exercício dos direitos e das liberdades fundamentais por pessoa com deficiência, visando à sua inclusão social e cidadania." (BRASIL, 2015, online, grifo nosso).

Com relação ao direito à educação da pessoa com deficiência, o Estatuto estabelece que esse e outros direitos devem ser assegurados pelo Estado, pela sociedade e pela família, in verbis:

Art. $8^{\circ}$ É dever do Estado, da sociedade e da família assegurar à pessoa com deficiência, com prioridade, a efetivação dos direitos referentes à vida, à saúde, à sexualidade, à paternidade e à maternidade, à alimentação, à habitação, à educação, à profissionalização, ao trabalho, à previdência social, à habilitação e à reabilitação, ao transporte, à acessibilidade, à cultura, ao desporto, ao 
turismo, ao lazer, à informação, à comunicação, aos avanços científicos e tecnológicos, à dignidade, ao respeito, à liberdade, à convivência familiar e comunitária, entre outros [...]. (BRASIL, 2015, online, grifo nosso).

O Estatuto promove ainda alterações no Código $\mathrm{Civil}^{3}$ no que tange à capacidade civil das pessoas com deficiência, que passam a ter plena capacidade civil, eis que revoga os incisos do artigo 3o do Código, o qual passa a estabelecer apenas em seu caput que: "Art. 3o São absolutamente incapazes de exercer pessoalmente os atos da vida civil os menores de 16 (dezesseis) anos." (BRASIL, 2002, online).

Há de se frisar que o supracitado Estatuto se origina da adequação da legislação brasileira à internacional. Isso porque o Estatuto é fruto da incorporação, no ordenamento jurídico brasileiro, da Convenção Internacional das Nações Unidas sobre os Direitos das Pessoas com Deficiência, de dezembro de 2006, e seu Protocolo Opcional ${ }^{4}$.

Promulgada pelo Decreto n. ${ }^{\circ}$ 6.949/2009, já em seu artigo 1ª a Convenção sobre os Direitos das Pessoas com Deficiência estabelece como propósito o respeito aos Direitos Humanos e as liberdades fundamentais das pessoas com deficiência:

Art. 1० O propósito da presente Convenção é promover, proteger e assegurar o exercício pleno e equitativo de todos os direitos humanos e liberdades fundamentais por todas as pessoas com deficiências e promover o respeito pela sua dignidade inerente (BRASIL, 2009, online).

A alteração no Código Civil de 2002, por parte da Convenção, decorre do previsto em seu artigo $4^{\circ}$, que trata das Obrigações Gerais:

3 Em que pese representar uma importante inovação legislativa, procurando assegurar a inclusão, o respeito à dignidade da pessoa humana e os direitos humanos, civilistas das mais variadas correntes tecem críticas acerca da forma como a alteração foi positivada. Ainda que não se constitua como objeto desta pesquisa, vale mencionar a existência desses posicionamentos. Entre eles, pode-se citar o de Anderson Schreiber, o qual entende que o Estatuto teve a oportunidade de redimensionar a questão da incapacidade, todavia não atingiu as expectativas de atualização nesse setor tradicionalmente intocável do Direito Civil. Segundo Schreiber, "O efeito disso é uma reforma tão restrita no regime de incapacidades que gera um resultado fraturado, em que os conceitos tradicionais do direito civil foram excepcionados de modo casuístico, sem uma efetiva e necessária reformulação. O excesso de preocupação com a terminologia - há passagens do Estatuto que parecem inspiradas unicamente no intuito de evitar expressões como "deficiente", "interdição" etc. - talvez tenha tirado o foco de questões centrais, de maior relevância, que não poderiam ter deixado de ser enfrentadas por uma reforma real e efetiva, como os critérios e o modo de avaliação do discernimento da pessoa para fins de curatela e a própria modulação dos efeitos da curatela, que se apresenta no texto do Estatuto como diretriz, mas sem parâmetros úteis àqueles que têm, diariamente, a tarefa de julgar pleitos de interdição." (SCHREIBER, 2020, p. 167-168).

4 Essa Convenção, até o momento, figura como sendo o único Tratado Internacional aprovado de acordo com o rito estabelecido pelo artigo $5^{\circ}, \S 3^{\circ}$, tornando-a equivalente à emenda constitucional. 
1. Os Estados Partes se comprometem a assegurar e promover o pleno exercício de todos os direitos humanos e liberdades fundamentais por todas as pessoas com deficiência, sem qualquer tipo de discriminação por causa de sua deficiência. Para tanto, os Estados Partes se comprometem a:

a) Adotar todas as medidas legislativas, administrativas e de qualquer outra natureza, necessárias para a realização dos direitos reconhecidos na presente Convenção;

b) Adotar todas as medidas necessárias, inclusive legislativas, para modificar ou revogar leis, regulamentos, costumes e práticas vigentes, que constituírem discriminação contra pessoas com deficiência (BRASIL, 2009, online, grifo nosso).

Pode-se entender por deficiência o impedimento ou a dificuldade - de natureza física, mental, intelectual ou sensorial - que diferencia, em algum desses aspectos, as pessoas com deficiência daquelas consideradas aptas a uma vida plena em sociedade - as ditas pessoas normais ${ }^{5}$.

A fim de dirimir eventuais dúvidas acerca de sua conceituação, a Lei n. ${ }^{\circ}$ 13.146/2015 traz o que considera como pessoa com deficiência:

Art. 20 Considera-se pessoa com deficiência aquela que tem impedimento de longo prazo de natureza física, mental, intelectual ou sensorial, o qual, em interação com uma ou mais barreiras, pode obstruir sua participação plena e efetiva na sociedade em igualdade de condições com as demais pessoas (BRASIL, 2015, online).

O Estatuto, em seu artigo 28, apresenta uma série de direitos e deveres aos quais incumbe ao poder público assegurar, criar, desenvolver, implementar, incentivar, acompanhar e avaliar, estabelecendo, em seu parágrafo $1^{\circ}$, que às instituições privadas se aplicam a maioria dos incisos, vedando, todavia, a cobrança de valores adicionais no cumprimento dessas determinações.

Por sua vez, o artigo 30 do Estatuto também estabelece outras determinações que devem ser cumpridas quando dos processos seletivos para ingresso e permanência nos cursos oferecidos, em que deverá ser adotada uma série de medidas (incisos I ao VII).

Por último, em 4 de agosto de 2015, os artigos 28, parágrafo 1º e 30, caput, da Lei n. ${ }^{\circ}$ 13.146/2015 foram questionados pela Confederação Nacional dos Estabelecimentos de Ensino - CONFENEN em uma Ação Direta de Inconstitucionalidade - ADI $5357 / \mathrm{DF}$, que pedia a declaração de sua inconstitucionalidade, eis que os citados artigos confrontariam direta e literalmente vários dispositivos constitucionais (artigos 5, caput e incisos XXII, XXIII e LIV; 170, incisos II e III; 205; 206, caput, incisos II e III; 208, caput, inciso III; 209; 227, caput,

5 A discussão sobre o que é ou não aceito como normal por uma dada sociedade, ainda que se revele rica e interessante, além de polêmica, não se configura como parte desta pesquisa. 
parágrafo $1^{\circ}$, inciso II, da Constituição Federal). Segundo a petição inicial, as instituições particulares encontrar-se-iam, entre outros, despreparadas para receber a incumbência em vários sentidos, causando desemprego e fechamento das escolas particulares, eis que o poder público estaria lançando sobre a iniciativa privada encargos e custos que seriam de sua responsabilidade.

Sob a relatoria do Ministro Edson Fachin, o Supremo Tribunal Federal - STF indeferiu, por maioria, o pedido de declaração de inconstitucionalidade. $O$ voto do relator foi seguido em maior ou menor medida pela quase totalidade dos demais ministros, com exceção do Ministro Marco Aurélio, que abriu divergência. Em seu voto, Fachin resumidamente entendeu que: i) a Convenção Internacional sobre os Direitos da Pessoa com Deficiência concretiza o princípio da igualdade; ii) o ensino inclusivo é um imperativo que se põe ao Estado; iii) a Constituição prevê em vários artigos a proteção da pessoa com deficiência; e iv) a pluralidade e a igualdade são duas faces da mesma moeda. O Acórdão menciona ainda que a Lei n. ${ }^{\circ}$ 13.146/2015 indica assumir o compromisso ético de acolhimento e pluralidade democrática, adotado pela Constituição, e que somente com o convívio com a diferença e o seu necessário acolhimento é que pode haver a construção de uma sociedade livre, justa e solidária, em que o bem de todos seja promovido sem preconceitos (BRASIL, 2017, p. 2-4).

\section{EDUCAÇÃO INCLUSIVA: UMA NECESSIDADE}

$\mathrm{Na}$ sociedade, existem diversos grupos de pessoas que sofrem segregação por suas particularidades. Um desses grupos é o das pessoas com deficiência, seja ela física, seja mental. Transportando essa realidade para o ambiente escolar, tem-se que, muitas vezes, as escolas não estão preparadas para receber alunos com deficiências e oferecer-lhes uma educação inclusiva.

Com efeito, histórica e culturalmente, parece que somos oriundos de uma educação cujo ideal sempre foi pautado no padrão de normalidade representado pela maioria, ignorando as diversidades e as particularidades dos indivíduos. Assim, o tratamento oferecido aos alunos com deficiência não costuma ser adequado, considerando suas necessidades e especificidades, o que exige a incorporação de uma educação que seja de fato inclusiva.

Essa realidade tampouco se trata apenas de um problema de metodologias de ensino, tendo em vista que existe a necessidade de olhar mais amplamente o contexto social da vida de cada aluno. Cada ser humano, em sua pessoalidade, assim como em sua dificuldade, traz consigo particularidades que exigem também olhares e escolhas próprias, bem como estratégias de ensinagem adequadas. (SILVA; CARVALHO, 2017, p. 301). 
Nesse sentido, ressalta-se que o contexto da educação inclusiva vai muito além da estratégia educacional a ser utilizada. É imprescindível questionar e remodelar também o cotidiano e a prática reiterada das escolas e dos professores.

A inclusão não pode ser considerada, de forma rasa, apenas como acesso à escola. Se os educandos - ou grupos ou indivíduos - fracassarem em seu processo de aprendizagem, se evadirem da instituição de ensino, repetirem anos escolares, aprenderem conteúdos sem relevância ou sentido, sofrerem abuso ou forem infelizes, o significado de tudo isso é que o sistema fracassou (STUBBS, 2008, p. 38).

A remodelação da educação e do processo educacional deve trazer um ensino de qualidade, que possa atender também às minorias, cuja necessidade de inclusão é urgente (SILVA, 2003, p. 374).

Quando se trata da inclusão, em seu mais intrínseco significado, depara-se diretamente com o desenvolvimento da criança, seja na perspectiva social, seja em sentido intelectual. Trata-se da socialização do indivíduo, que, tantas vezes, é excluído no ambiente escolar (SANCHES; ARRUDA, 2014, p. 2).

Dessa forma, não há que se considerar apenas a inserção dessas crianças no sistema. Faz-se necessária, também, a inclusão, que objetiva incluir a criança especial, regularmente, desde o início de seu processo educacional (WERNECK, 1997, p. 52).

Portanto, a educação inclusiva implica o abandono dos termos acesso e inserção, pois não se trata simplesmente de inserir a pessoa com deficiência no ambiente escolar, dar-lhe acesso formal. A educação inclusiva vai além, pois exige uma interação com todos os atores da vida escolar, compatibilizando-a com os aspectos sociais e individuais dos alunos com deficiência.

A educação inclusiva e a possibilidade de uma remodelação escolar vislumbram, a termo, a igualdade de aprendizado, não se limitando apenas às questões de reconhecimento da diversidade.

Dessa forma, para que a educação inclusiva, de fato, ocorra, as escolas devem readequar-se, buscando suprir as dificuldades pessoais de cada aluno, bem como oferecer a possibilidade de todos atingirem o mesmo nível de conhecimento e aprendizado, cada um a sua maneira e a seu tempo. Assim, devem ser utilizados recursos diversificados, os quais criem e aperfeiçoem estratégias, para garantir um processo de ensinagem eficiente e equiparar diferenças e oportunidades.

Muito embora o país esteja na direção correta, no sentido da inclusão, muito ainda tem que ser feito sobre essa temática, sendo necessária a restruturação não somente da parte econômica e estrutural, como também a qualificação dos profissionais da educação (CROCHIK et al., 2006, p. 57-58). 
É importante entender a realidade de cada pessoa, individualizando cada ser humano, bem como potencializando as capacidades de cada um - a ótica deve ser a valorização de cada indivíduo, independentemente das diferenças. A condição de deficiência não deveria constituir-se em elemento para valorar ou discriminar seres humanos.

A fim de entender a extrema necessidade da educação inclusiva, basta olhar para a história - ela contém uma gama de situações de preconceitos e de exclusão. (BUCCIO; BUCCIO, 2008, p. 99).

Conforme abordado na seção anterior, no Brasil, já há uma ordem normativa constitucional e infraconstitucional - que permite garantir os direitos à educação das pessoas com deficiência. No entanto, para que a educação inclusiva ocorra a contento e de forma sustentável, apenas a previsão legal é insuficiente, fazendo-se necessária também uma mudança de postura da sociedade como um todo, não só daqueles diretamente envolvidos. Deve haver uma interação e um efetivo engajamento entre diversos elementos e atores, podendo-se citar poder público, escolas, uso de estratégias pedagógicas, famílias, qualificação profissional dos professores, entre outros.

\section{EDUCAÇÃO INCLUSIVA E COMBATE AO PRECONCEITO}

O preconceito é um termo muito conhecido e discutido de forma recorrente na sociedade contemporânea, todavia, para a sua existência, faz-se necessário que os indivíduos julgassem uns aos outros com base em valores e não em conhecimentos. Os grandes atingidos pelo preconceito são as pessoas que não se enquadram no padrão médio de homem ou mulher, por motivos físicos ou intelectuais.

Há um fenômeno, chamado bullying, que existe há muito tempo e, provavelmente, já foi vivenciado por todas as pessoas, como autores, vítimas ou simplesmente testemunhas. As pessoas com deficiência normalmente são alvo dessa prática com maior intensidade, assim como todas as demais classes de pessoas para as quais a educação inclusiva se volta, como indígenas e quilombolas.

Como anota Koing (2013, p. 16-17), "não se deve banalizar o bullying por isso". Justamente pela recorrência, por vezes, torna-se algo comum, visto como normal. A educação inclusiva, por sua vez, é categoria antagônica ao bullying e a qualquer forma de discriminação e preconceito.

Em uma sociedade em que a produtividade é feita em série, depara-se com o crescimento de estereótipos à medida que se deixa o conteúdo em detrimento da forma. Trata-se de uma sociedade em que o juízo de valor se instala em detrimento do juízo de fato. 
Pode-se enfatizar que os valores, os quais dão base aos julgamentos de hoje, não são os mesmos do passado. Com o passar do tempo, os julgamentos se modificaram, mas sempre enfaixados por valores pré-concebidos (HORKHEIMER; ADORNO, 1985, p. 188).

O sistema educacional acaba por seguir esse mesmo roteiro, permanecendo alheio às necessidades geradas por diferentes indivíduos e grupos, favorecendo a homogeneização. Pouco vai além. Ocupa-se, via de regra, apenas com a educação estereotipada, visto que essa gera a comodidade de se educar por meio de limites preestabelecidos, sem a trabalhosa tarefa de se buscar o melhor para cada indivíduo e para cada um dos diferentes grupos de pessoas (FERREIRA, 2007, p. 549).

A educação inclusiva é extremamente complexa, pois é necessário o abandono da condescendência para dar lugar à aceitação da diferença, trazendo cada indivíduo para ocupar seu espaço dentro do mundo, encontrando sua identidade (CARDOSO, 2012, p. 25).

Um ambiente escolar inclusivo aceita a diversidade dentro da escola, trata a diferença como algo que enriquece as relações pessoais, ao invés de vê-la como um fardo a ser carregado. É preciso, além de tudo, tratar todos como iguais dentro das diferenças e das complexidades de cada um (CÉSAR, 2003, p. 119).

Nesse contexto, é de extrema importância que se possa enfatizar a capacidade da educação para mudar a realidade, tornando a inclusão efetiva. Para isso, é necessário que os processos, os quais ocorrem no espaço escolar, sejam conduzidos por pessoas preparadas e receptivas em relação aos indivíduos com deficiência, por possuírem limitações físicas ou psicológicas.

A escola precisa ser o espaço onde cada indivíduo tenha a liberdade de manifestar suas habilidades particulares, bem como de compartilhar suas dificuldades. Dessa forma, a educação pode ser o principal instrumento de modificação da realidade discriminatória atualmente existente (SILVA, 2009, p. 13).

É necessário ressaltar que todo ser humano - seja ele quem for - possui características próprias e é especial, único e insubstituível e que isso não muda, mesmo quando, entre as diferenças, esteja uma deficiência. Todos os indivíduos têm o seu próprio papel na sociedade e contribui, de alguma forma, para o crescimento social (CARDOSO, 2012, p. 25).

O ideal da educação inclusiva implica que a diversidade não seja motivo para negar a igualdade de direitos. A valoração negativa de determinados seres humanos discriminando-os - decorre, em parte, da ausência de tratamento igualitário (LIMA, 2006, p. 21). 
É sabido que as debilidades acarretadas pela deficiência não devem ser ocultadas, mas admitidas e respeitadas, na medida em que essa exposição reforce a interdependência entre os indivíduos, proporcionando uma relação honesta de apoio e troca. O déficit deve deixar de ser uma barreira de valoração para se tornar uma ponte de transição de conhecimento e experiência (DHANDA, 2008, p. 50).

Todos os indivíduos têm um papel positivo na sociedade, não sendo diferente com as pessoas com deficiência, tendo em vista que muitas delas podem contribuir de forma efetiva para a sociedade. É importante lembrar que existem, no mundo atual, milhões de pessoas com deficiência, sendo, dessa forma, necessário derrubar as barreiras que impedem a sua inclusão e a sua contribuição para a sociedade (KI-MOON, 2012).

Transcendendo as diferenças e acolhendo as pessoas, em suas individualidades, dá-se às pessoas a experiência da troca, da educação diversificada e do respeito. Isso permite ingressar em uma concepção que exige um novo modelo de escola o qual permite o desenvolvimento interdisciplinar e, sobretudo, interpessoal e social dos alunos (MIRANDA, 2004, p. 6).

Em uma democracia, material e efetiva, não apenas as pessoas com deficiência possuem o direito de conviver com as demais, como também todos os demais indivíduos têm o direito - e também o dever - de conviver com as pessoas com deficiência. A pluralidade e o respeito às diferenças são da essência dos regimes democráticos.

Cabe dizer, em outras palavras, que as pessoas com deficiência têm direito a uma plena e inclusiva educação, bem como que as demais pessoas possuem o direito de conviver com as diferenças para seu próprio aprimoramento e formação.

É cediço que o Brasil está longe do ideal pretendido com a educação inclusiva, porém é necessária sua efetivação para combater o preconceito e a segregação na sociedade, começando pelo ambiente educacional.

\section{PAPEL DOCENTE}

A educação, em um contexto geral, coloca para a categoria profissional dos docentes um papel central. $O$ professor não é só instrumento de criação e disseminação do conhecimento, mas sim de socialização, visto que atua na formação de todas as demais categorias profissionais existentes.

Nesse sentido, ele atua, na educação inclusiva, não apenas com a missão de tornar as particularidades de cada indivíduo em potencialidades - e não em limitações a serem segregadas - como também tem o papel social de trabalhar, com os demais alunos a erradicação da discriminação e do preconceito em relação aos alunos que possuam toda e qualquer diferença no que se refere ao "padrão de normalidade". 
Por toda perspectiva de idealização e de mudança pretendida com educação inclusiva, torna-se central a figura do professor enquanto coordenador de um processo gradativo de socialização para a aceitação e a convivência com as diferenças - inclusive físicas e intelectuais.

É por intermédio desses profissionais que a educação inclusiva se tornará bemsucedida e verdadeiramente integradora. $O$ aluno portador de deficiência pode, em muitos momentos e por motivos variados, considerar-se incapaz, frustrado enquanto pessoa. Daí a importância da presença de um profissional apto a enxergar além, bem como propiciar a esse aluno um retorno capaz de fortalecer sua autoconfiança e de ampliar sua capacidade de conhecer (RAIÇA; OLIVEIRA, 1990, p. 9).

No sistema atual, há carência de professores cuja formação inclua competências e habilidades para trabalhar com essa realidade, oferecendo acompanhamento adequado aos portadores de deficiência. A escola se propõe a ser o principal meio de socialização de conhecimento quantitativa e qualitativamente válido. O problema é que o aumento da demanda de aprendizagem - e de inclusão dos portadores de deficiência - não tem sido acrescido, na mesma proporção, de profissionais na quantidade e na qualidade necessárias (DESTRO, 2003, p. 64).

A formação e a qualificação profissional dos professores, contemporaneamente, devem estar diretamente ligadas à remodelação educacional voltada a educar além das diferenças ou das limitações de cada um. Uma educação ao alcance de todos, tanto por seus meios estruturais e recursos didáticos quanto pela capacitação dos educadores para trabalhar com alunos e em situações antes desconhecidas (SILVA, 2009, p. 15).

O papel social do profissional da educação remete para muito além da atuação didática desempenhada nas escolas. É importante lembrar que todos os demais profissionais passaram, em algum momento, por salas de aula - foram alunos. Portanto, o papel docente de socialização e conscientização sobre a realidade social é primordial.

É, em grande parte, por meio do processo de ensinagem que os alunos desenvolvem sua relação com o conhecimento e, como consequência, desenvolvem a forma pela qual vão atuar no mundo - comportamentos são aprendidos em sala de aula e reproduzidos no mundo externo. Em um mundo em que a educação escolar ganha importância, o profissional da educação assume grande influência sobre cada aluno em sala de aula. Nesse contexto, o professor passa a ser um elemento central na luta contra o preconceito, a intolerância e a discriminação (DESTRO, 2003, p. 67).

É importante deixar claro que não se está desconhecendo o papel desempenhado pela família nesse contexto. A família - e o grupo social de convivência - são fontes primárias de reprodução do preconceito, da intolerância e da discriminação. Porém, o objetivo deste artigo é destacar a importância do papel da escola e do docente nesse 
processo. A socialização e a conscientização dos alunos podem ir além deles, ajudando a modificar também a forma de pensar e agir de suas famílias e grupo social.

Os profissionais da educação devem ser incentivadores da solidariedade, do respeito e da tolerância - devem ser inclusivos. Nesse sistema, em seu ideal, o professor deixa de ser quem está à frente para sentar-se ao lado e compartilhar todas as formas de conhecimento que possam agregar intelectualmente, psicologicamente e socialmente (STUBBS, 2008, p. 126).

A empatia, vista como a capacidade de se colocar no lugar do outro, de procurar sentir o que o outro sente, é fundamental nesse processo. Ela permite compreender as emoções, os sentimentos e as ações do outro. Agir com empatia deve fazer parte do agir pedagógico voltado à inclusão. Nele é necessário experimentar e compreender o que o outro sente e pensa - e como isso influencia o seu agir.

Importa que, diante dessa necessária mudança do sistema educacional, sejam buscados meios os quais, implantados, tornam mais eficazes a educação inclusiva (DELORS et al., 1998, p. 159). Não basta apenas o comprometimento docente, visto que o apoio institucional ocupa grande parte desse processo de mudança. É responsabilidade da instituição escolar proporcionar o acesso aos novos conhecimentos necessários, bem como os meios necessários (SILVA, 2017, p. 306).

Nessa perspectiva, Estado, família, comunidade, gestores escolares e professores têm o dever de, conjuntamente, promover a educação de todo e qualquer cidadão, propiciando condições para que assuma seu papel e sua responsabilidade dentro do ambiente em que vive. Nesse contexto, é importante perceber que, se os professores têm responsabilidades - que são grandes -, por outro lado, possuem também direitos, o que inclui e ajuda do meio social em que estão inseridos.

Não é possível prover uma educação de qualidade - e muito menos uma educação de qualidade e inclusiva - sem que haja uma soma de esforços, incluindo Estado, comunidade e instituições de ensino. Embora ocupe um papel central nesse processo, não é possível colocar no professor toda a responsabilidade.

Em relação à Educação Básica, importa ressaltar a relevância de uma formação diferenciada de seus professores. É na infância que a criança desenvolverá tanto sua individualidade quanto seu processo de socialização. Relativamente ao seu recrutamento e à sua formação, é possível destacar elementos que têm se demonstrado efetivos ao redor do mundo (DELORS et al., 1998, p. 159):

a) forma de recrutamento - é responsável pela melhor seleção em relação a esses profissionais, em especial, em termos de formação, competência profissional e didática. Portanto, é necessário adotar formas adequadas de seleção; 
b) formação inicial - é necessário que esses profissionais estejam aptos a exercer suas funções, comprovadamente formados e diplomados ou certificados;

c) formação contínua - é por meio dela que os profissionais da educação, com o passar do tempo, podem reconhecer as mudanças e manterem-se atualizados e preparados. Ao passo que as tecnologias se desenvolvem, o professor precisa conhecê-las e dominá-las;

d) professores responsáveis pela formação pedagógica - é necessária uma atenção especial em relação a esses profissionais, visto que são eles os responsáveis pelo primeiro contato dos futuros professores com o mundo educacional. É preciso um maior cuidado com a preparação e o aperfeiçoamento desse grupo específico de docentes;

e) controle - é o instrumento de troca entre os responsáveis pela avaliação institucional e os profissionais da educação. Nesse processo, não basta exercer o controle sobre o método de aprendizagem ou mesmo em relação ao professor, é necessário que, como contrapartida ao controle, haja a interação com as ideias e o planejamento, buscando, conjuntamente, as melhores soluções para cada situação-problema;

f) gestão - é preciso reformular a gestão escolar, visto que os professores, por si só, não serão capazes de implementar todas as mudanças necessárias; inclui o necessário apoio de outros profissionais, como assistentes sociais, psicólogos escolares, etc.;

g) participação de agentes exteriores à escola - é preciso responsabilizar não apenas aos atores diretos da educação; é necessária a parceria entre pais e professores. Quando a educação no lar é positiva, certamente traz benefícios dentro da escola também;

h) condições de trabalho - é certo que todo trabalho, para ser bem executado, depende, em grande parte, das condições em que é desenvolvido. Certamente uma remuneração digna e a valorização dos professores terão forte influência sobre seu desempenho profissional;

i) meios de ensino - é preciso possibilitar a utilização, no processo de ensinagem, das novas tecnologias e dos meios cada vez mais diversificados desenvolvidos contemporaneamente.

Por fim, o autor destaca a importância dos professores: todo o processo educacional depende, grandemente, do seu desempenho. Assim, a valorização desses profissionais se torna elemento central. Isso inclui o apoio dos demais profissionais da educação, assim como da família e do próprio aluno. 
É de extrema importância, ainda, que os professores tenham um vasto conhecimento em relação à política de educação inclusiva, estejam atentos para compreender suas especificidades e, principalmente, tenham, também, o apoio de profissionais especializados - trata-se de comunhão de habilidades e conhecimentos (SILVA, 2017, p. 306).

É justamente por meio do conhecimento dessas especificidades que o processo educacional será capaz de ir além do que ainda ocorre atualmente na maioria das escolas, passando a entender cada ser humano enquanto indivíduo, correlacionando, por meio das adequações pertinentes, cada qual com as suas necessidades. Esse modelo deverá ser responsável pela valorização de cada aluno, derrubando as barreiras de imposição que tanto afastam determinadas pessoas - ou grupos de pessoa - do ambiente escolar (SILVA, 2017, p. 305).

Destaque-se, novamente, a importância da parceria entre a instituição educacional, a família e o professor para que se possa concretizar um ambiente social capaz de incluir quem hoje se isola. Esse conjunto de relações interinstitucionais e interpessoais - de trocas entre os componentes desse grupo - facilita pensar e moldar um processo de ensinagem eficaz para cada aluno individualmente, respeitando as diferenças. Permite, também, priorizar as habilidades e reconfigurar as dificuldades (SILVA, 2017, p. 303).

O maior desafio - e também a melhor solução - é exatamente reconfigurar a educação de forma que ela possa proporcionar a cada ser humano o que ele, individualmente, necessita. Deve-se deixar de pensar apenas na generalidade da formação e pensar também nas especificidades. É necessário suprir a educação de um método capaz de intervir na formação das atuais gerações - incluindo os portadores de necessidades especiais -, dando-lhes um futuro melhor e mais justo (SILVA, 2017, p. 302).

É possível evidenciar, segundo pesquisa realizada por Ferreira (2007), que, mesmo com todos os recursos à disposição, o papel do professor permanece central:

Foi possível perceber, durante a pesquisa de campo, que o sucesso ou insucesso da aprendizagem da criança com deficiência é, muitas vezes, o reflexo da intervenção pedagógica e do perfil do professor que com ela atua como mediador no processo ensino-aprendizagem (FERREIRA, 2007, p. 554).

Isso decorre da situação de ser o professor o agente que mais tem contato com o estudante - seja qual for a idade e o nível em que se encontra no sistema educacional. Assim, é de extrema importância que tenha domínio da matéria ensinada e perícia na pedagogia empregada, bem como empatia por seus alunos. Todavia, mesmo sendo o 
principal ator da relação educacional, não é o único. Demanda de uma base formada por gestão escolar, infraestrutura para o trabalho, metodologias adotadas, etc.

\section{CONSIDERAÇÕES FINAIS}

Diante do exposto, é possível afirmar que a educação inclusiva, se utilizada corretamente, é um instrumento eficaz para o combate ao preconceito à pessoa com deficiência nos estabelecimentos educacionais, bem como na sociedade como um todo, eis que seus efeitos podem ser sentidos para além da sala de aula.

Nesse sentido, para que a educação inclusiva possa ocorrer em sua plenitude, fazse necessário cumprir com o já positivado na legislação brasileira, tanto de ordem constitucional como infraconstitucional, no cumprimento da Meta 4 do PNE, no respeito à Convenção Internacional das Nações Unidas sobre os Direitos das Pessoas com Deficiência, incorporada como emenda constitucional no ordenamento jurídico brasileiro pela Lei Brasileira de Inclusão da Pessoa com Deficiência - LBPD (Estatuto da Pessoa com Deficiência).

Faz-se necessária, também, uma preparação adequada do ambiente escolar como um todo (escola, estratégias educacionais e professores), além do envolvimento familiar e comunitário. Sem embargo, a figura do professor tem um papel de grande relevância não só para o ensino em geral, mas também de forma especial para a educação inclusiva. No presente artigo, adota-se como pressuposto o entendimento de que o abandono à ideia de inserção e a sua substituição pela inclusão só são possíveis com o auxílio do profissional docente.

O professor não se configura apenas como provedor de conhecimentos, mas também de ensinamentos de vida e de conscientização dos problemas sociais, que não são, como durante muito tempo se pensou, relativos apenas ao ambiente externo aos estabelecimentos de ensino. A escola é atingida por tudo o que ocorre na realidade de seus alunos e suas famílias, na comunidade que a cerca e na sociedade, no país em que está inserida; é também coprodutora do que ocorre nesse mundo.

O papel do professor ganha ainda mais destaque quando se considera que é o docente o qual mantém contato constante com o estudante, mais do que qualquer outra pessoa. Em muitas situações reais, até mesmo, os pais e a família têm menos contato com os alunos do que os próprios docentes.

É necessário, assim, anotar que o professor é o maior e o principal ator da educação inclusiva. No entanto, para desempenhar o seu trabalho de forma adequada, diversos fatores devem ser considerados: atuação da gestão escolar, infraestrutura e material adequado, formação apropriada e contínua, dentre outros. 
$\mathrm{Na}$ educação inclusiva, o professor deve não só dominar os conteúdos sob sua responsabilidade, como também a pedagogia e as metodologias adequadas de ensinagem. Quando se trata de educação inclusiva, todos os fatores e as responsabilidades são ampliados - porque o professor trabalha com grandes diferenças em sala de aula - sendo necessário um terceiro fator que é a empatia.

\section{REFERÊNCIAS}

BRASIL. [Constituição (1988)]. Constituição Federal da República Federativa do Brasil de 1988. Brasília, DF: Presidência da República, 1988. Disponível em: http://www.planalto.gov.br/ccivil_03/constituicao/constituicao.htm. Acesso em: 6 abr. 2020.

BRASIL. Decreto no 6.949, de 25 de agosto de 2009. Promulga a Convenção Internacional sobre os Direitos das Pessoas com Deficiência e seu Protocolo Facultativo, assinados em Nova York, em 30 de março de 2007. Brasília, DF: Presidência da República, 2009. Disponível em: http://www.planalto.gov.br/ccivil_ 03/_ato2007-2010/2009/decreto/d6949.htm. Acesso: em 6 abr. 2020.

BRASIL. Lei no 10.406, de 10 de janeiro de 2002. Institui o Código Civil. Brasília, DF: Presidência da República, 2002. Disponível em: http://www.planalto.gov.br/ccivil_03/ leis/2002/L10406.htm. Acesso em: 6 abr. 2020.

BRASIL. Lei no 13.146, de 6 de julho de 2015. Institui a Lei Brasileira de Inclusão da Pessoa com Deficiência (Estatuto da Pessoa com Deficiência). Brasília, DF: Presidência da República, 2015. Disponivel em: http://www.planalto.gov.br/ccivil_03/_Ato20152018/2015/Lei/L13146.htm. Acesso em: 6 abr. 2020.

BRASIL. Lei no 13.005, de 25 de junho de 2014. Aprova do Plano Nacional de Educação - PNE e dá outras providências. Brasília, DF: Presidência da República, 2014. Disponível em: http://www.planalto.gov.br/ccivil_03/_ato20112014/2014/lei/113005.htm. Acesso em: 14 jul. 2020.

BRASIL. Supremo Tribunal Federal. Inteiro teor do acórdão - ADI 5.357. Relator: Min. Edson Fachin, 2017. Disponível em: http://redir.stf.jus.br/paginadorpub/ paginador.jsp?docTP=TP\&docID=12012290. Acesso em: 6 abr. 2020.

BUCCIO, Maria Isabel; BUCCIO, Pedro Augustinho. Educação especial: uma história em construção. Curitiba: IBPEX, 2008.

CARDOSO, Alenilton da Silva. A educação especial e inclusiva na perspectiva da dignidade humana. Revista Em Tempo, Marília, SP, v. 11, p. 11-26, 2012. Disponível em: https://revista.univem.edu.br/emtempo/article/view/330. Acesso em:_20 jul. 2020. 
CÉSAR, Margarida. A escola inclusiva enquanto espaço-tempo de diálogo de todos para todos. In: RODRIGUES, David (org.). Perspectivas sobre a Inclusão: da Educação à Sociedade. Porto: Porto Editora, 2003.

CROCHIK, José Leon et al. Psicologia Argumento, Curitiba, v. 24, n. 46 p. 55-70, jul./set. 2006. Disponível em: https://periodicos.pucpr.br/index.php/psicologiaar gumento/article/view/20117. Acesso em: 14 jul. 2020.

DELORS, Jacques et al. Educação um tesouro a descobrir: relatório para a UNESCO da comissão internacional sobre educação para o século XXI. 2. ed. Brasília, DF: Cortez Editora, 1998. Disponível em: https://www.pucsp.br/ecopolitica/documentos/ cultura_da_paz/docs/relatorio_dellors.pdf. Acesso em: 14 jul. 2020.

DESTRO, Martha Rosa Pisani. Desafios do professor. In: A educação no século 21: desafios e perspectivas. São Paulo: UNASPRESS, 2003.

DIAS, Marília Costa. Atendimento educacional especializado complementar e a deficiência intelectual: considerações sobre a efetivação do direito à educação. São Paulo: USP, 2010. Disponível em: https://www.teses.usp.br/teses/disponiveis /48/48134/tde-20042010-161739/publico/MARILIA_COSTA_DIAS.pdf. Acesso em: 8 jun. 2020.

FERREIRA, Maria Elisa Caputo. O enigma da inclusão: das intenções às práticas pedagógicas. Educação e Pesquisa, São Paulo, v. 33, n. 3, p. 543-560, 2007. Disponível em: https://www.scielo.br/pdf/ep/v33n3/a11v33n3.pdf. Acesso em: 14 jul. 2020.

HORKHEIMER, Max; ADORNO, Theodor W. Elementos do antissemitismo. In: ADORNO, Theodor; HORKHEIMER, Max (org.). Dialética do esclarecimento. Rio de Janeiro: Jorge Zahar, 1985.

IBGE. Censo Demográfico de 2010. 2010. Disponível em: https://www.ibge.gov.br/estatisticas/sociais/populacao/9662-censo-demografico2010.html?=\&t=destaques. Acesso em: 6 abr. 2020.

KI-MOON, Ban. Mensagem no Dia Internacional das Pessoas com Deficiência: 2012. Secretário Geral. Organização das Nações Unidas (ONU). 3 dez. 2012. Disponível em: http://unicrio.org.br/dia-internacional-das-pessoas-com-deficiencia-3-de-dezembro-de2012/. Acesso em: 2 abr. 2020.

KOING, Evelin Sofia R. Bullying: a Responsabilidade Civil e o Dever de Indenização. 2013. 109 f. Dissertação (Mestrado) - Curso de Direito, Pontifícia Universidade Católica de São Paulo, São Paulo, 2013. p. 16-17. Disponível em:

https://tede2.pucsp.br/handle/handle/6216. Acesso em: 14 jul. 2020. 
LIMA, Francisco José de. Ética e inclusão: o estatus da diferença. In: MARTINS, Lúcia de Araújo Ramos et al. (org.). Inclusão: compartilhando saberes. Petrópolis: Vozes, 2006. p. 54-66.

MIRANDA, Arlete Aparecida Bertoldo. História, Deficiência e Educação Especial, Campinas: Unicamp, 2004. p. 1-7.

RAIÇA, Darcy; OLIVEIRA, Maria Teresa Baptista de. A Educação especial do deficiente mental. São Paulo: E.P.U., 1990.

RAZABONI JUNIOR, Ricardo Bispo; LEÃO JÚNIOR, Teófilo Marcelo de Arêa; SANCHES, Raquel Cristina Ferraroni. A educação inclusiva para pessoas com deficiência e o papel da UNESCO. Revista da Faculdade de Direito da UFRGS, Porto Alegre, n. 38, p. 140-153, ago. 2018. Disponível em: https://seer.ufrgs.br/revfacdir/article/view/77562. Acesso em: 14 jul. 2020.

SANCHES, Patrícia Aparecida Squarça; ARRUDA, Apareceida Luvizotto Medina Martins. Educação Especial: inclusão que gera a exclusão. Revista Eletrônica Saberes da Educação, v. 5, n. 1, 2014. Disponível em: http://docs.uninove.br/arte/fac/publica coes_pdf/educacao/v5_n1_2014/Patricia.pdf. Acesso em: 14 jul. 2020.

SCHREIBER, Anderson. Manual de direito civil contemporâneo. 3. ed. São Paulo: Saraiva Educação, 2020. Versão eletrônica.

SILVA, Lidia Martins. da. Educação Inclusiva e Formação de Professores. Curso de Pós-Graduação Latu Sensu à distância. Instituto Federal de Educação, Ciência e Tecnologia do Estado de Mato Grosso. Cuiabá, 2009. Disponível em: https://bento.ifrs.edu.br/site/midias/arquivos/2010069353641lidia_monografia.pdf. Acesso em: 2 abr. 2020.

SILVA, Naiane Cristina; CARVALHO, Beatriz Girão Enes. Compreendendo o Processo de inclusão Escolar no Brasil na Perspectiva dos Professores: uma Revisão integrativa. Revista Brasileira de Educação Especial, Marília, SP, v. 23, n. 2, p. 293-308, abr./jun. 2017. Disponível em: https://doi.org/10.1590/s1413-65382317000200010. Acesso em: 14 jul. 2020.

SILVA, Simone Cerqueira da. Interação entre professora e alunos em sala inclusiva. 2003. Dissertação (Mestrado em Educação) - Universidade Estadual Paulista Júlio de Mesquita Filho - UNESP, Marília, 2003. Disponível em: https://repositorio.unesp.br/handle/11449/91259. Acesso em: 14 jul. 2020.

SILVA, Simone Cerqueira; ARANHA, Maria Salete Fábio. Interação entre professora e alunos em salas de aula com proposta pedagógica de educação inclusiva. Revista Brasileira de Educação Especial. Marília, v. 11, n. 3, p. 373-394, set./dez. 2005. Disponível em: https://doi.org/10.1590/S1413-65382005000300005. Acesso em: 14 jul. 2020. 
STUBBS, Sue. Educação Inclusiva: onde existem poucos recursos. Oslo: The Atlas Alliance, 2008.

UNESCO. Declaração de Salamanca e Enquadramento de Acção. Salamanca, Espanha, 1994. p. 11-12.

WERNECK, Claudia. Ninguém mais vai ser bonzinho na sociedade inclusiva. Rio de Janeiro: WVA,1997.

\section{NOTA}

Contribuição de cada coautor:

Marcelo Vitor Silva Rizzo - realizou a primeira parte da pesquisa e redigiu a versão inicial do texto, com 14 páginas.

Gabriela Natacha Bechara - realizou revisão integral do texto, com relevante ampliação da pesquisa e redação da versão final do texto, que chegou a 24 páginas.

Horácio Wanderlei Rodrigues - revisou a primeira versão do artigo, corrigindo integralmente a redação e à adequação à ABNT; também complementou parcialmente a pesquisa e o texto inicial, ampliando-o para 18 páginas. Ao final realizou a revisão definitiva do trabalho, após a ampliação realizada por Gabriela Natacha Bechara.

\section{Como citar este documento:}

BECHARA, Gabriela Natacha; RODRIGUES, Horácio Wanderlei; RIZZO, Marcelo Vitor Silva. Educação inclusiva para pessoas com deficiência: protagonismo docente e combate ao preconceito. Revista Opinião Jurídica, Fortaleza, v. 18, n, 29, p. 198-220, set./dez. 2020. 